\title{
Carbon and electron flow in Clostridium butyricum grown in chemostat culture on glycerol and on glucose
}

\author{
S. Abbad-Andaloussi, C. Dürr, G. Raval and H. Petitdemange \\ Author for correspondence: H. Petitdemange. Tel: +338391 20 53. Fax: +3383912550.
}

Laboratoire de chimie Biologique I, Université Henri Poincare, Nancy I, BP 239, 54506 Vandœuvre-lèsNancy Cédex, France

\begin{abstract}
The metabolism of Clostridium butyricum DSM 5431 was studied in chemostat culture under carbon limitation using either glucose or glycerol. On glycerol, the enzymes glycerol dehydrogenase, diol dehydratase and 1,3-propanediol (1,3-PD) dehydrogenase constitute the branch point that partitions the carbon flux between the competing pathways, i.e. formation of either 1,3-PD or acetate and butyrate. The increasing levels of these enzyme activities with increasing dilution rates $(D)$ explained the constant proportion of glycerol conversion into 1,3-PD. The production of acetate or butyrate constitutes another important branch point and when $D$ increased (i) large amounts of intracellular acetyl-CoA accumulated, (ii) the carbon flux switched from butyric acid to acetic acid, (iii) the specific activity of thiolase was not affected, suggesting this enzyme may be the bottleneck for carbon flux to butyrate biosynthesis providing an explanation for the accumulation of large amounts of intracellular acetyl-CoA, and (iv) high levels of NADH were found in the cell. Oxidation of NADH by 1,3-PD dehydrogenase was linked to the production of 3-hydroxypropionaldehyde (3-HPA) by glycerol dehydratase. The fact that high intracellular concentrations of NADH were found means that diol dehydratase activity is the rate-limiting step in 1,3-PD formation, avoiding the accumulation of 3-HPA which is a very toxic compound. The specific rate of glucose catabolism $\left(q_{\text {glucose }}=11.1 \mathrm{mmol} \mathrm{h}^{-1} \mathrm{~g}^{-1}\right)$ was around four times lower than the specific rate of glycerol catabolism $\left(q_{\text {glycerol }}=57.4 \mathrm{mmol} \mathrm{h}^{-1} \mathrm{~g}^{-1}\right)$. On glucose-grown cells, reducing equivalents which are released in the glycolytic pathway were reoxidized by the butyric pathway and the low specific formation rate of butyric acid led to an increase in the intracellular level of acetyl-COA and NADH. Carbon flow was higher on glycerol due to the reoxidation of NADH by both butyric and PD pathways.
\end{abstract}

Keywords: Clostridium butyricum, glycerol catabolism, glucose catabolism, carbon flow, electron flow

\section{INTRODUCTION}

Over recent years there has been an increase in research and development efforts involving clostridial fermentation, namely the fermentation of glucose by butyric acid bacteria (Woods, 1993). Clostridia are able to ferment the carbon source to a variety of end-products by means of branched fermentation pathways. Generally, the different branches of fermentation are not equivalent with respect to the generation of energy or reducing equivalents, and

Abbreviations: DHA, dihydroxyacetone; fd, ferredoxin; 3-HPA, 3hydroxypropionaldehyde; PD, propanediol. the amount of reduced versus neutral and oxidized products has the potential for a great deal of natural variation. It was shown (Jungermann et al., 1973; Petitdemange et al., 1976) that the reduced electron carrier ferredoxin (fd) plays a pivotal role in electron distribution in the cell in that it can either transfer electrons via hydrogenase to generate hydrogen or transfer electrons to the pyridine nucleotides via the appropriate fd oxidoreductase. The activities of three enzymes, NADH-fd oxidoreductase, NADPH-fd oxidoreductase and hydrogenase are responsible for controlling the electron flow, which in turn determines the carbon flow within the cell.

Clostridium butyricum is known as a classical acid producer 


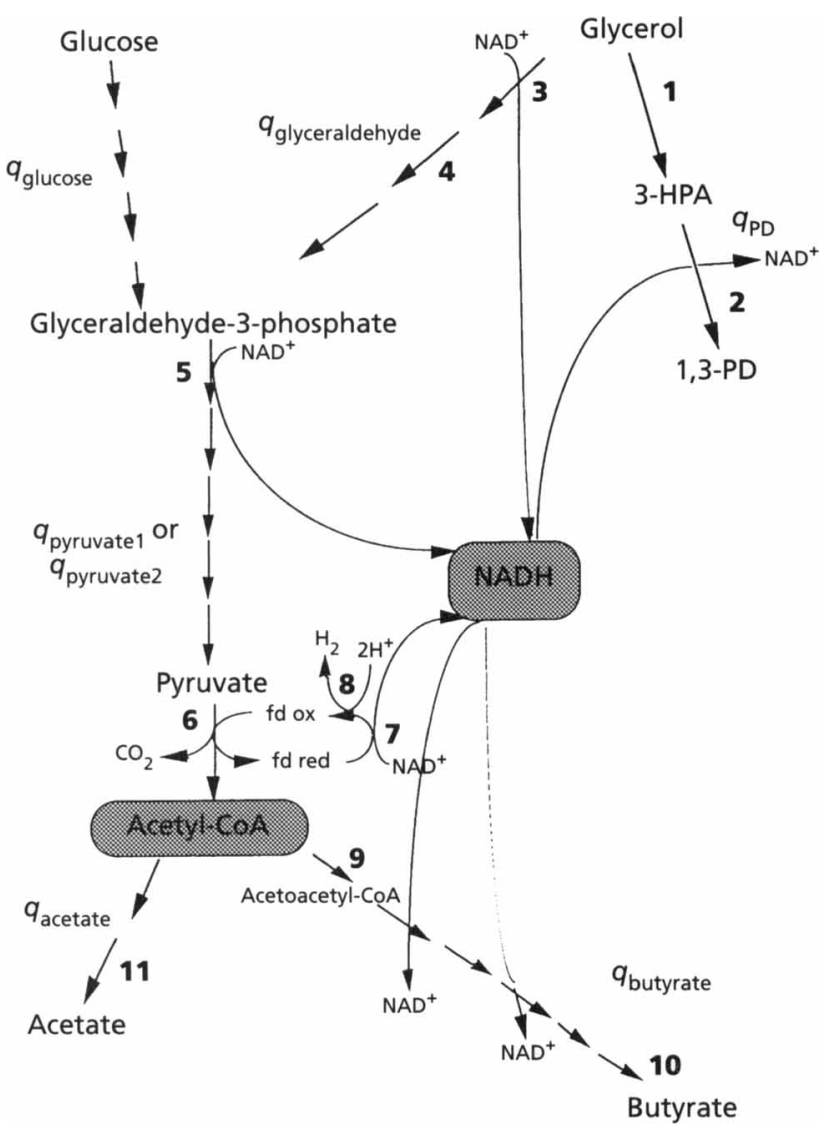

Fig. 1. Schematic diagram depicting the catabolism of glucose and glycerol by $C$. butyricum. 1, Diol dehydratase; 2, 1,3-PD dehydrogenase; 3, glycerol dehydrogenase; 4, DHA kinase; 5 , glyceraldehyde-3-P dehydrogenase; 6 , phosphoroclastic reaction; 7, NADH-fd oxidoreductase; 8, hydrogenase; 9, thiolase; 10 , butyrate kinase; 11 , acetate kinase. $q_{\text {glycerol }}=$ $q_{\mathrm{PD}}+q_{\text {pyruvate }} ; q_{\text {pyruvate } 1}=2 q_{\text {glucose }} ; q_{\text {pyruvate2 }}=q_{\text {glycerol }}-q_{\mathrm{PD}}$.

and usually ferments carbohydrates to butyrate, acetate, $\mathrm{CO}_{2}$ and molecular hydrogen. Usually about $2 \mathrm{~mol} \mathrm{CO}$ and $2.5 \mathrm{~mol} \mathrm{H}_{2}$ are produced per mol hexose catabolized (Jungermann et al., 1973). The production of acetate or butyrate constitutes an important branch point (Fig. 1). C. butyricum is also able to catabolize glycerol and an additional branch point of fermentation exists (Fig. 1): glycerol can be either oxidized to dihydroxyacetone (DHA) and subsequently phosphorylated to yield DHAP, or it can be dehydrated to 3-hydroxypropionaldehyde (3HPA). The latter compound is then reduced to 1,3propanediol (1,3-PD). Fermentative utilization of glycerol, a more reduced substrate than glucose, requires the disposal of the two extra hydrogen atoms; this could be accomplished by stimulating $\mathrm{H}_{2}$ production. Surprisingly, the reducing power is not used to form $\mathrm{H}_{2}$, but rather a more reduced compound, 1,3-PD. The concentrations of the fermentation end-products have been extensively studied in C. butyricum (Biebl, 1991; Biebl et al., 1992; Günzel, 1991; Günzel et al., 1991; Heyndrickx et al., 1991b); in all fermentations the yield of 1,3-PD from glycerol was higher than expected from NADH pro- duction by acid formation. In contrast, $\mathrm{H}_{2}$ production was lower than expected, if it is assumed that one $\mathrm{mol} \mathrm{H}_{2}$ is released per mol acetyl-CoA formed. So nothing is known about how the oxidation/reduction state is balanced during glycerol catabolism. Also, very little is known regarding the regulation of the acetate/butyrate ratio when $C$. butyricum is growing on glucose, except that the excess $\mathrm{H}_{2}$ is formed by NADH-fd reductase activity to balance the amount of acetate made (Jungermann $e t$ al., 1973).

From the scheme shown in Fig. 1, it is interesting to note that when glycerol and glucose are used as carbon sources for the growth of $C$. butyricum, the carbon metabolism pathway from glyceraldehyde-3-P to pyruvate is the same but there is a different distribution of the electron flow since during glucose fermentation more $\mathrm{H}_{2}$ is produced than $\mathrm{CO}_{2}$ (Jungermann et al., 1973), whereas glycerol fermentation yields considerably less $\mathrm{H}_{2}$ than $\mathrm{CO}_{2}$ (Biebl et al., 1992). This is why in this paper, we deal with the metabolic aspect of $C$. butyricum when grown on glucose or glycerol, using continuous culture, an obvious tool to unravel metabolic regulation. Furthermore, to understand the observed changes in metabolism in the steady-state chemostat culture, the level of the key enzyme activities and the $\mathrm{NAD}^{+}, \mathrm{NADH}$ and acetyl-CoA pools were analysed. C. butyricum DSM 5431 was chosen for this study because it has been used in several investigations relating to the various events which take place during glycerol metabolism (Biebl, 1991; Biebl et al., 1992; Günzel, 1991; Günzel et al., 1991).

\section{METHODS}

Chemicals. All chemicals were reagent grade. Enzymes and coenzymes were obtained from Sigma. All gases used were purchased from Air Liquide.

Organism and medium. C. butyricum DSM 5431 was used. The spores of the strain were stored at $4{ }^{\circ} \mathrm{C}$ in $\mathrm{RCM}$ (Reinforced Clostridial Medium purchased from Oxoid). Clostridium pasteurianum ATCC 6013 was grown in the same medium as $C$. butyricum but with glucose as carbon source.

The preculture medium contained the following components ( 1 distilled $\left.\mathrm{H}_{2} \mathrm{O}\right)^{-1}$ : glycerol, $20 \mathrm{~g} ; \mathrm{K}_{2} \mathrm{HPO}_{4}, 1.0 \mathrm{~g} ; \mathrm{KH}_{2} \mathrm{PO}_{4}$, $0.5 \mathrm{~g} ;\left(\mathrm{NH}_{4}\right)_{2} \mathrm{SO}_{4}, 2.0 \mathrm{~g} ; \mathrm{MgSO}_{4} .7 \mathrm{H}_{2} \mathrm{O}, 0.2 \mathrm{~g} ; \mathrm{CaCl}_{2} .2 \mathrm{H}_{2} \mathrm{O}$, $15 \mathrm{mg} ; \mathrm{FeSO}_{4} .7 \mathrm{H}_{2} \mathrm{O}, 5 \mathrm{mg} ; \mathrm{CaCO}_{3}, 2 \cdot 0 \mathrm{~g}$; yeast extract, $1.0 \mathrm{~g}$; trace element solution SL7 (Biebl \& Pfenning, 1982), $2 \mathrm{ml}$. The growth temperature was $32^{\circ} \mathrm{C}$.

Fermentation modes. Continuous cultures were carried out aseptically in a 21 bioreactor (LSL-Biolafitte, 21 growth vessel with a $1 \mathrm{l}$ working volume). The temperature was set at $32{ }^{\circ} \mathrm{C}$ and $\mathrm{pH}$ kept at 7 with $2 \mathrm{M} \mathrm{KOH}$. Anaerobic conditions were maintained by sparging with nitrogen. Agitation was kept constant at 100 r.p.m. The culture volume was kept constant at 11 by automatic regulation of the culture level. The bioreactor was inoculated $(10 \%, \mathrm{v} / \mathrm{v})$ with exponential preculture. The culture was grown in batches for $12 \mathrm{~h}$ before the medium flow was started at a low dilution rate $(D)$. Two substrates were used in this study, glycerol at a concentration of $10 \mathrm{~g} \mathrm{l}^{-1}$ and glucose at 1,3 and $10 \mathrm{~g} \mathrm{l}^{-1}$.

Analytical methods. Glycerol was determined enzymically via glycerol kinase, pyruvate kinase and L-lactate dehydrogenase 
using the Boehringer test kit and instructions. Glucose was assayed with hexokinase and glucose-6-phosphate dehydrogenase using the Boehringer diagnostic kit. Concentrations of 1,3-PD, acetic and butyric acids were determined by GC (Intersmat IGC $121 \mathrm{FL}$, equipped with a flame ionization detector). Separation took place in a glass column $(2 \mathrm{~m} \times 2 \mathrm{~mm}$ i.d.) packed with chromosorb 101/80-100 mesh. Nitrogen was used as the carrier gas with n-butanol as the internal standard and the temperature of the column was $170^{\circ} \mathrm{C}$. Data were analysed with an Intersmat ICR IB Integrator.

The cell concentrations were estimated by cell dry weight measurements using a predetermined correlation between $A_{650}$ (Shimatzu UV160A double beam spectrophotometer) and cell dry weight.

Preparation of cell free extracts. Cells were centrifuged at $12000 \mathrm{~g}$ for $15 \mathrm{~min}$; after washing with Tris buffer $(50 \mathrm{mM}$ Tris/ $\mathrm{HCl}, 2 \cdot 0 \mathrm{mM}$ DTT, $0.1 \mathrm{mM} \mathrm{MnSO}, \mathrm{pH} 7 \cdot 4$ ) cells were resuspended in this buffer. The cells were sonicated at $2{ }^{\circ} \mathrm{C}$ four times for $20 \mathrm{~s}$ at a frequency of $20 \mathrm{kcycles} \mathrm{s}^{-1}$, separated by $60 \mathrm{~s}$ (MSE, 150 watt ultrasonic disintegrator). The supernatant was collected from the cell lysate following centrifugation at $12000 \mathrm{~g}$ for $20 \mathrm{~min}$ at $4{ }^{\circ} \mathrm{C}$. At each step, extracts were maintained under anaerobic conditions. To measure hydrogenase activity, cellfree extract was prepared as described but without washing.

Protein concentrations of cell extracts were determined according to the Bradford (1976) method, using crystalline bovine serum albumin as standard.

\section{Enzyme assays.}

Hydrogenase (EC 1.18.99.1) in the direction of methyl viologen reduction was assayed as described by Junelles et al. (1988), modified as follows: $60 \mathrm{mM}$ potassium phosphate buffer (pH 7.2), $20 \mathrm{mM}$ methyl viologen, $140 \mathrm{mM} \beta$-mercaptoethanol under a hydrogen atmosphere.

fd-NAD ${ }^{+}$reductase $(E C$ 1.18.1.3) was assayed with pyruvate as the reductant of fd and under a $\mathrm{CO}$ atmosphere according to Petitdemange et al. (1976), modified by the addition of $1 \mathrm{mM}$ purified fd (Sigma).

$\mathrm{NADH}-\mathrm{fd}$ reductase was measured by metronidazole reduction according to the method of Blusson et al. (1981).

Glycerol dehydrogenase (EC 1.1.1.6) and 1,3-PD dehydrogenase (EC $1.1 .1 .202)$ activities were measured by the linear increase in $A_{340}$ produced by addition of cell extracts (Ruch et al., 1974). The assays contained the following components: $100 \mathrm{mM}$ glycerol or 1,3-PD, $2 \mathrm{mM} \mathrm{NAD}$, $30 \mathrm{mM}$ ammonium sulfate and $100 \mathrm{mM}$ potassium carbonate buffer $(\mathrm{pH} 9 \cdot 0)$.

Diol dehydratase (PD dehydratase, EC 4.2.1.28) activity was determined by the 3-methyl-2-benzothiazolinone hydrazone (MBTH) method according to Toraya et al. (1977). The assays contained the following components: $0.2 \mathrm{M} 1,2 \mathrm{PD}, 0.05 \mathrm{M}$ $\mathrm{KCl}, 0.035 \mathrm{M}$ potassium phosphate buffer $(\mathrm{pH} 7 \cdot 0), 15 \mu \mathrm{M}$ adenosylcobalamin and an appropriate amount of cell extract in a total volume of $1 \mathrm{ml}$. After incubation at $37^{\circ} \mathrm{C}$ for $10 \mathrm{~min}$, the enzyme reaction was stopped by adding $1 \mathrm{ml} 0.1 \mathrm{M}$ potassium citrate buffer ( $\mathrm{pH} \mathrm{3.6)}$ and $0.5 \mathrm{ml} 0.1 \% \mathrm{MBTH}$ hydrochloride. After $15 \mathrm{~min}$ at $37^{\circ} \mathrm{C}, 1 \mathrm{ml}$ water was added and the amount of propionaldehyde was determined from $A_{305}$. The apparent molar extinction coefficient at $305 \mathrm{~nm}$ for the coloured product formed from propionaldehyde in the MBTH method was $13.3 \times 10^{3} \mathrm{M}^{-1} \mathrm{~cm}^{-1}$

Acetate kinase (EC 2.7.2.1) and butyrate kinase (EC 2.7.2.7). The enzymic activities were determined by the analytical procedure for acetyl-phosphate (Lipmann \& Tuttle, 1945). Enzyme activities were assayed in a volume of $0.8 \mathrm{ml}$ containing ( $\mathrm{mmol}$ ): Tris/ $\mathrm{HCl}$ buffer $(\mathrm{pH} \mathrm{7.5)}, 40$; potassium acetate or potassium butyrate, 160 ; manganese sulfate, $2 \cdot 4$; ATP, 4 . The reaction was initiated by addition of crude extract. After $5 \mathrm{~min}$ at $37^{\circ} \mathrm{C}$, $0.2 \mathrm{ml}$ hydroxylamine $(2.1 \mathrm{M}, \mathrm{pH} 6.4$, freshly neutralized) was added. After $5 \mathrm{~min}$ at room temperature, the reaction was stopped by addition of $0.2 \mathrm{ml}$ TCA $(15 \%, w / v), 0.2 \mathrm{ml} \mathrm{HCl}$ $(4 \mathrm{M})$ and $0.2 \mathrm{ml} \mathrm{FeCl}_{3}(5 \%, \mathrm{w} / \mathrm{v}$, in $0.1 \mathrm{M} \mathrm{HCl})$. The amounts of acetyl hydroxamate or butyryl hydroxamate formed were determined at $540 \mathrm{~nm}$ using a standard curve obtained with purified acetate kinase, since acetyl hydroxamate and butyryl hydroxamate have identical extinction coefficients (Lipmann \& Tuttle, 1945).

Phosphoroclastic activities. Assays were based on ability to catalyse formation of acetyl phosphate in pyruvate oxidation as described by Mortenson et al. (1963), modified as follows: $25 \mathrm{mM}$ potassium phosphate buffer ( $\mathrm{pH} \mathrm{6.5)}, 1 \mathrm{mM}$ sodium pyruvate, $0.05 \mathrm{mM}$ CoA and $1 \mathrm{mM}$ methyl viologen.

Thiolase. The condensation reaction of two molecules of acetylCoA forming acetoacetyl-CoA and CoASH was followed by measuring the oxidation of $\mathrm{NADH}$, coupled with the reduction of acetoacetyl-CoA by $\beta$-hydroxyacyl-CoA dehydrogenase (Lynen et al., 1952). With the regenerating system, acetylphosphate and phosphotransacetylase plus $\mathrm{CoASH}$, activities were determined as described by Berndt \& Schlegel (1975). A cuvette contained: $100 \mathrm{mM}$ Tris $/ \mathrm{HCl}$ buffer, $\mathrm{pH} 8 \cdot 2,0.63 \mathrm{mM}$ CoASH, $20 \mathrm{mM}$ acetyl-phosphate and $5 \mu \mathrm{l}$ phosphotransacetylase $\left(2 \mathrm{mg} \mathrm{ml}^{-1}\right)$. The mixture was incubated for $10 \mathrm{~min}$, then the reaction was started by adding $0.30 \mathrm{mM} \mathrm{NADH}, 5 \mu \mathrm{l} \beta$ hydroxyacyl-CoA dehydrogenase $\left(2 \mathrm{mg} \mathrm{ml}^{-1}\right)$ and $10 \mu \mathrm{l}$ cell extract.

Determination of $\mathrm{NAD}^{+}$and $\mathrm{NADH}$ pools. Levels of $\mathrm{NAD}^{+}$, $\mathrm{NADH}$ and acetyl-CoA were measured after extraction of a culture broth sample, neutralization and filtration. Samples of $4 \mathrm{ml}$ were taken quickly from the bioreactor with sterile syringes and immediately put into tubes containing the extractant, without separating the cells from the medium.

$\mathrm{NAD}^{+}$was extracted with $\mathrm{HCl}(\mathrm{NADH}$ and $\mathrm{NADPH}$ were degraded) and NADH was extracted with $\mathrm{KOH}\left(\mathrm{NAD}^{+}\right.$and $\mathrm{NADP}^{+}$were degraded) as described by Wimpenny \& Firth (1972). Before assays for NADH, this coenzyme was converted to $\mathrm{NAD}^{+}$with D-lactate dehydrogenase (EC 1.1.1.28) (Klingenberg, 1965). $\mathrm{NAD}^{+}$was assayed with a $\mathrm{NAD}(\mathrm{H})$ specific alcohol dehydrogenase (EC 1.1.1.1) (Klingenberg, 1965; Vasconcelos et al., 1994) and the resulting NADH was determined by fluorometry (Hitachi, model F-2000) and by spectrophotometry.

Determination of intracellular acetyl-CoA. Acetyl-CoA was extracted with perchloric acid as described by Decker (1965). The level of acetyl-CoA was determined by a method described by Tubbs \& Garland (1969) using citrate synthase (EC 4.1.3.7) and malate dehydrogenase (EC 1.1.1.37). The citrate synthase consumes oxaloacetate and acetyl-CoA, and so displaces the equilibrium of the reaction catalysed by malate dehydrogenase; thus acetyl-CoA removal causes the formation of $\mathrm{NADH}_{2}$, which can be measured spectrophotometrically.

All enzyme assays, except acetate and butyrate kinase, were performed under anaerobic conditions. Each enzyme assay was done in duplicate on three extracts. One unit of enzyme activity is defined as the amount of enzyme that catalyses the conversion of $1 \mu \mathrm{mol}$ substrate $\min ^{-1}$.

Calculations. The main products of glycerol fermentation by $C$. butyricum were 1,3-PD, butyrate and acetate (Biebl et al., 1991) (see Fig. 1). The minimum or maximum amount of NADH 
formed can be calculated according to the equations of glycerol conversion to acetate and butyrate:

glycerol $+2 \mathrm{NAD}^{+}+2 \mathrm{ADP}+2 \mathrm{P}_{i} \rightarrow$ acetate $+\mathrm{CO}_{2}+\mathrm{H}_{2}+2 \mathrm{NADH}+2 \mathrm{ATP}$

$\mathrm{NADH}$ is formed by glycerol dehydrogenase and glyceraldehyde-3-P dehydrogenase. ATP is formed by phosphoglycerate kinase, pyruvate kinase and acetate kinase, whereas DHA kinase uses one ATP.

If reduced $\mathrm{fd}$ is not reoxidized by hydrogenase but is entirely reoxidized by the fd-NAD ${ }^{+}$reductase according to:

$\mathrm{NAD}^{+}+\mathrm{fd}$ red $\rightarrow \mathrm{NADH}+\mathrm{fd}$ ox

the conversion of glycerol to acetate becomes:

glycerol $+3 \mathrm{NAD}^{+}+2 \mathrm{ADP}+2 \mathrm{P}_{\mathrm{i}} \rightarrow$

acetate $+\mathrm{CO}_{2}+3 \mathrm{NADH}+2 \mathrm{ATP}$

The minimum amount of $\mathrm{NADH}$ formed via the acetate pathway is $2 \mathrm{~mol}$ and the maximum $\mathrm{NADH}$ is $3 \mathrm{~mol}$, hence the corresponding production of 1,3-PD must be between 2 and 3 mol.

Conversion of glycerol to butyrate can be written as:

2 glycerol $+2 \mathrm{NAD}^{+}+3 \mathrm{ADP}+3 \mathrm{P}_{\mathrm{i}} \rightarrow$

butyrate $+2 \mathrm{H}_{2}+2 \mathrm{CO}_{2}+2 \mathrm{NADH}+3 \mathrm{ATP}$

On the assumption that the reduced fd is entirely reoxidized by the fd- $-\mathrm{NAD}^{+}$reductase activity rather than being released as molecular $\mathrm{H}_{2}$ via hydrogenase, the conversion of glycerol to butyrate becomes:

2 glycerol $+4 \mathrm{NAD}^{+}+3 \mathrm{ADP}+3 \mathrm{P}_{\mathrm{i}} \rightarrow$

butyrate $+2 \mathrm{CO}_{2}+4 \mathrm{NADH}+3 \mathrm{ATP}$

Four moles of NADH results from the production of $2 \mathrm{~mol}$ by glycerol dehydrogenase and $2 \mathrm{~mol}$ by glyceraldehyde-3-P dehydrogenase, whereas $2 \mathrm{~mol}$ are used by 3-hydroxybutyryl-CoA dehydrogenase and butyryl-CoA dehydrogenase. The minimum amount of NADH formed via the butyrate pathway is $2 \mathrm{~mol}$ and the maximum NADH is $4 \mathrm{~mol}$, hence the corresponding production of 1,3-PD must be between 2 and $4 \mathrm{~mol}$.

In glucose catabolism, acetate formation can be written:

glucose $+2 \mathrm{NAD}^{+}+4 \mathrm{ADP}+4 \mathrm{P}_{\mathrm{i}} \rightarrow$

2acetate $+2 \mathrm{CO}_{2}+2 \mathrm{H}_{2}+2 \mathrm{NADH}+4 \mathrm{ATP}$

ATP is formed by phosphoglycerate kinase, pyruvate kinase and acetate kinase. The minimum amount of NADH formed via the acetate pathway is 2 mol NADH produced by glyceraldehyde-3-P dehydrogenase and the maximum amount is $4 \mathrm{~mol}$ on the assumption that the reduced fd is entirely reoxidized by the fd-NAD ${ }^{+}$reductase activity.

Glucose conversion to butyrate can be written:

glucose $+3 \mathrm{ADP}+3 \mathrm{P}_{1} \rightarrow$ butyrate $+2 \mathrm{CO}_{2}+2 \mathrm{H}_{2}+3 \mathrm{ATP}$

ATP is formed by phosphoglycerate kinase, pyruvate kinase and butyrate kinase. The formation of butyrate is redox neutral since the 2 mol NADH produced by glyceraldehyde-3-P dehydrogenase are used in butyrate biosynthesis, but the maximum $\mathrm{NADH}$ is $2 \mathrm{~mol}$ if the reduced $\mathrm{fd}$ is entirely reoxidized by the fd- $-\mathrm{NAD}^{+}$reductase.

The specific rate of pyruvate formation with glycerol as substrate was calculated as follows:

$q_{\text {glycerol }}-q_{\mathrm{PD}}=q_{\text {pyruvate }}=q_{\text {glyceraldehyde }}$

where $q_{\mathrm{glycerol}}, q_{\mathrm{PD}}, q_{\text {pyruvate }}$ and $q_{\mathrm{glyceraldenyde}}$ are the specific rates of glycerol used, 1,3-PD formation, pyruvate formation and glyceraldehyde formation, respectively, all in units of $[\mathrm{mmol}(\mathrm{g}$ dry wt cells $\left.)^{-1} \mathrm{~h}^{-1}\right]$.

The specific rate of $\mathrm{NADH}$ production with glycerol as substrate by the fd-NAD ${ }^{+}$reductase activity $\left(q_{\mathrm{fd}-\mathrm{NAD}}\right)$ is the difference between the specific rate of NADH consumption $\left(q_{\mathrm{NADH}}\right)$ to form end-products and the specific rate of NADH production $\left(q_{\text {NADHproduct }}\right)$ during substrate conversion to pyruvate.

$q_{\mathrm{fd}-\mathrm{NAD}}=q_{\mathrm{NADH} \text { cons }}-q_{\mathrm{NADH} \text { product }}$

$q_{\mathrm{NADHcons}}=q_{\mathrm{PD}}+2 q_{\text {butyrate }}$

$q_{\mathrm{NADHproduct}}=2 q_{\text {pyruvate }}$

With glucose as substrate, the specific rate calculation becomes:

$q_{\mathrm{xADH}-\mathrm{fd}}=q_{\text {pyruvate }}-q_{\text {butyrate }}=q_{\text {excessNADH }}$

where $q_{\text {glucose }}$ is the specific rate of glucose used in units of [mmol ( $\mathrm{g}$ dry wt cells) $\left.{ }^{-1} \mathrm{~h}^{-1}\right]$.

\section{RESULTS}

\section{Carbon flow in C. butyricum grown in continuous culture under glycerol limitation}

Data on the effect of $D$ on growth and product formation with C. butyricum are compiled in Table 1 . No significant concentration of residual glycerol was observed at $D$ values of up to $0 \cdot 26 \mathrm{~h}^{-1}$. The dry weight was almost constant between $0.04 \mathrm{~h}^{-1}$ and $0.26 \mathrm{~h}^{-1}$ and decreased markedly at $0.30 \mathrm{~h}^{-1}$ corresponding to glycerol accumulation.

Whatever the $D$ value, conversion of glycerol into 1,3-PD was between 0.57 and 0.60 [mol PD (mol glycerol $)^{-1}$ ] showing that the carbon flux distribution through diol dehydratase and 1,3-PD dehydrogenase was balanced by the flux through glycerol dehydrogenase and DHA kinase. These facts were confirmed by study of the specific rates of glycerol utilization and product formation. Fig. 2 shows the linearity of the specific rates of glycerol utilization and 1,3-PD and pyruvate formation as a function of $D$. Whereas at low $D$ values, the cells produced more butyrate than acetate, at high $D$ values, i.e. high carbon flux, a switch was observed and the cells produced more acetate than butyrate (Fig. 3).

Below a $D$ of $0.15 \mathrm{~h}^{-1}$, i.e. $q_{\text {pyruvate }}=11.9 \mathrm{mmol} \mathrm{h}^{-1} \mathrm{~g}^{-1}$, the specific rate of butyrate formation increased more rapidly than the specific rate of acetate formation (Fig. 3). Between 0.15 and $0.26 \mathrm{~h}^{-1}$ there is an increase of the specific rate of acetate formation concomitant with a decrease of the specific rate of butyrate formation. The fact that the quantities of 1,3-PD formed were greater than the quantities of NADH generated (between $0.04 \mathrm{~h}$ and $0.26 \mathrm{~h}^{-1}$, Table 1 ) in the catabolic reactions from glycerol to pyruvate suggested the existence of another source of NADH. Part of the reduced fd was reoxidized by the fd-NAD ${ }^{+}$reductase; the specific rate of NADH generation by this activity increased from 0.8 to $4.5 \mathrm{mmol} \mathrm{h}^{-1} \mathrm{~g}^{-1}$ in parallel with an increase in growth rate from 0.04 to $0.26 \mathrm{~h}^{-1}$. At a $D$ of $0.30 \mathrm{~h}^{-1}$, due to the 
Table 1. Effect of $D$ on growth and product formation by C. butyricum DSM 5431 grown under glycerol- or glucoselimited chemostat cultures

Data in parentheses are SD values from four determinations. NA, not applicable.

\begin{tabular}{|c|c|c|c|c|c|c|c|c|c|c|c|c|}
\hline \multirow[t]{2}{*}{ Input } & \multirow[t]{2}{*}{$D\left(\mathrm{~h}^{-1}\right)$} & \multirow{2}{*}{$\begin{array}{c}\text { Biomass } \\
\left(\mathrm{g} \mathrm{l}^{-1}\right)\end{array}$} & \multirow{2}{*}{$\begin{array}{c}\text { Substrate } \\
\text { used }(\mathrm{mM})\end{array}$} & \multicolumn{3}{|c|}{ Products ( $\mathrm{mmol} \mathrm{1}^{-1}$ ) } & \multirow[t]{2}{*}{ Ac/But } & \multirow{2}{*}{$\begin{array}{l}\text { Conversion [mol } \\
\text { PD (mol } \\
\text { glycerol) })^{-1} \text { ] }\end{array}$} & \multirow{2}{*}{$\begin{array}{l}\text { Carbon } \\
\text { recovery } \\
(\%)\end{array}$} & \multicolumn{2}{|c|}{ NADH (mmol) } & \multirow{2}{*}{$\begin{array}{c}\text { NADH } \\
\text { recovery } \\
(\%)\end{array}$} \\
\hline & & & & Acetate & Butyrate & 1,3-PD & & & & $\min$ & $\max$ & \\
\hline \multirow{5}{*}{$\begin{array}{l}\text { Glycerol } \\
(108 \cdot 5 \mathrm{mM})\end{array}$} & $0 \cdot 04$ & $0 \cdot 64(0-07)$ & $108(13 \cdot 1)$ & $5.3(0.6)$ & $21 \cdot 1(1 \cdot 2)$ & $62(3 \cdot 0)$ & 0.25 & 0.57 & 101 & 52.8 & $100 \cdot 3$ & 61 \\
\hline & 0.08 & $0.64(0.08)$ & $108(12 \cdot 3)$ & $5.1(0.5)$ & $20 \cdot 4(2 \cdot 1)$ & $64 \cdot 6(3.5)$ & 0.25 & 0.60 & 102 & 51 & 96.9 & $66 \cdot 6$ \\
\hline & $0 \cdot 15$ & $0.57(0.06)$ & $108(12 \cdot 2)$ & $5.4(0.5)$ & $19 \cdot 2(0 \cdot 9)$ & $62 \cdot 8(2 \cdot 9)$ & 0.28 & 0.58 & $98 \cdot 7$ & $49 \cdot 2$ & 93 & 67.5 \\
\hline & 0.26 & $0.60(0.07)$ & $107 \cdot 4(10 \cdot 6)$ & $7.9(0.9)$ & $15 \cdot 4(1 \cdot 4)$ & $64.8(3.5)$ & $0 \cdot 51$ & 0.60 & $96 \cdot 4$ & $46 \cdot 6$ & $85 \cdot 3$ & 75.9 \\
\hline & 0.30 & $0.33(0.02)$ & $63 \cdot 1(5 \cdot 2)$ & $13 \cdot 8(1 \cdot 2)$ & $3.7(0.8)$ & $36.6(1.5)$ & 3.73 & 0.58 & $91 \cdot 6$ & 35 & $56 \cdot 2$ & $65 \cdot 1$ \\
\hline \multirow{2}{*}{$\begin{array}{l}\text { Glucose } \\
(5.55 \mathrm{mM})\end{array}$} & 0.08 & $0 \cdot 18(0.11)$ & $5 \cdot 4(0 \cdot 6)$ & $4 \cdot 8(1 \cdot 3)$ & $2 \cdot 7(1 \cdot 8)$ & $\mathrm{NA}$ & $1 \cdot 8$ & $\mathrm{NA}$ & 91 & 9.6 & $24 \cdot 6$ & 22 \\
\hline & $0 \cdot 30$ & $0.19(0.02)$ & $5 \cdot 2(0 \cdot 4)$ & $5.9(0.9)$ & $3.6(0.7)$ & $\mathrm{NA}$ & 1.6 & $\mathrm{NA}$ & $94 \cdot 6$ & $11 \cdot 8$ & 19 & $30 \cdot 5$ \\
\hline
\end{tabular}

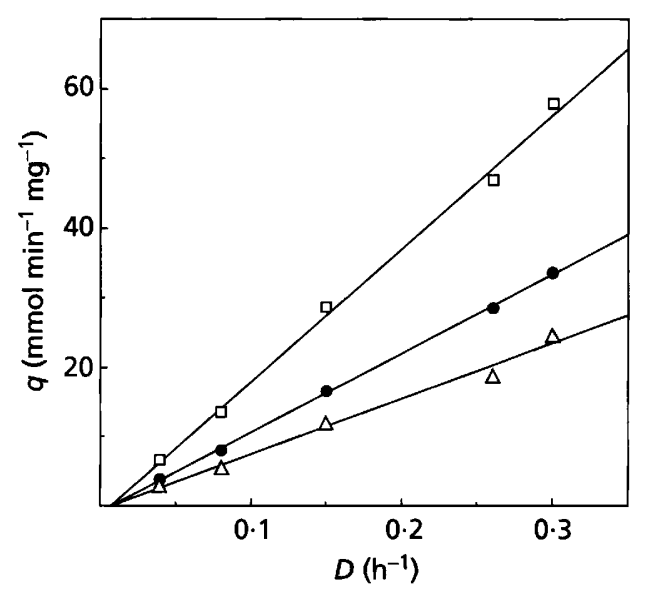

Fig. 2. Influence of $D$ on specific rates of glycerol utilization and PD production in a continuous culture of $C$. butyricum. The glycerol input concentration was $108 \mathrm{mM} . \square, q_{\text {glycerol }} ; q_{\mathrm{PD}}$; $\triangle, q_{\text {glyceraldehyde }}=q_{\text {pyruvate }}$.

limitation of the butyrate pathway, the NADH produced by glycerol dehydrogenase and glyceraldehyde-3-P dehydrogenase was sufficient for the formation of 1,3-PD.

\section{Carbon flow in C. butyricum grown in continuous culture with glucose}

Cultures were grown in a chemostat at glucose concentrations of $5.55,16.6$ and $55.5 \mathrm{mM}$ (Table 2). Whereas with a glycerol-limited medium a rate of glycerol consumption of $46.5 \mathrm{mmol} \mathrm{h}^{-1} \mathrm{~g}^{-1}$ was obtained without residual glycerol (Fig. 2, $D=0 \cdot 26 \mathrm{~h}^{-1}$ ), a specific rate as low as $2 \cdot 1 \mathrm{mmol}$ glucose $\mathrm{g}^{-1} \mathrm{~h}^{-1}$ led to residual glucose (Table 2). With a glucose input of $55.5 \mathrm{mM}$ only 55 and $26 \%$ was used at $D=0.08$ and $0.30 \mathrm{~h}^{-1}$, respectively.

Fig. 1 compares glycerol and glucose as carbon sources for growth. They show a number of differences in catabolism but have in common the pathway from

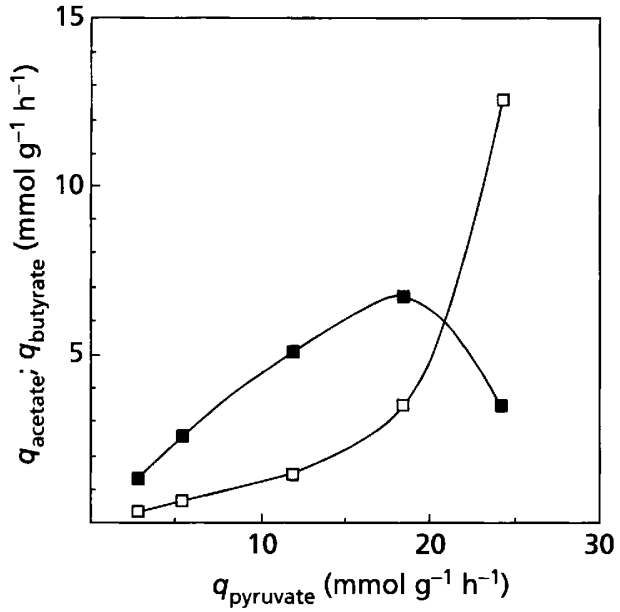

Fig. 3. Influence of the specific rates of pyruvate production in a continuous culture of $C$. butyricum on specific rates of acetate and butyrate production. The glycerol input concentration was $108 \mathrm{mM}$. $\square, q_{\text {acetate }} ; \mathbf{\square}, q_{\text {butyrate }}$.

glyceraldehyde-3-P to pyruvate. The lower rate of glucose catabolism $\left(q_{\text {glucose }}=11.1 \mathrm{mmol} \mathrm{h}^{-1} \mathrm{~g}^{-1}\right.$, Table 2$) \mathrm{com}-$ pared to that of glycerol catabolism $\left(q_{\text {glycerol }}=\right.$ $57.4 \mathrm{mmol} \mathrm{h}^{-1} \mathrm{~g}^{-1}$, Fig. 2) cannot be explained by a change in the activity of this pathway which remained almost the same for culture on glycerol $\left(q_{\text {pyruvate }}=\right.$ $24 \cdot 2 \mathrm{mmol} \mathrm{h}^{-1} \mathrm{~g}^{-1}$, Fig. 2$)$ or on glucose $\left(q_{\text {pyruvate }}=\right.$ $22 \cdot 2 \mathrm{mmol} \mathrm{h}^{-1} \mathrm{~g}^{-1}$, Table 2).

Glucose-grown cultures produced butyrate and acetate. The difference between the specific production rate of $\mathrm{NADH}$ and the specific consumption rate indicates an excess of NADH which was reoxidized by the NADH-fd reductase and the reduced fd reoxidized by hydrogenase. The specific rate of NADH oxidation by the NADH-fd reductase increases in parallel with the specific rates of substrate consumption. 
Table 2. Catabolic pathway fluxes of glucose chemostat

Pathway flux values are expressed in $\mathrm{mmol} \mathrm{h}^{-1} \mathrm{~g}^{-1}$.

\begin{tabular}{|c|c|c|c|c|c|c|c|c|}
\hline Glucose (mM) & $D\left(\mathbf{h}^{-1}\right)$ & Substrate used (mM) & Biomass $\left(\mathrm{g} \mathrm{l}^{-1}\right)$ & $\boldsymbol{q}_{\text {glucose }}$ & $q_{\text {pyruvate }}$ & $\boldsymbol{q}_{\text {acetate }}$ & $q_{\text {butyrate }}$ & $q_{\text {NADH-fd }}$ \\
\hline \multirow[t]{2}{*}{5.55} & $0 \cdot 08$ & $5 \cdot 4$ & $0 \cdot 18$ & $2 \cdot 4$ & $4 \cdot 8$ & $2 \cdot 1$ & $1 \cdot 2$ & 3.6 \\
\hline & $0 \cdot 30$ & $5 \cdot 2$ & $0 \cdot 19$ & $8 \cdot 2$ & $16 \cdot 4$ & $9 \cdot 3$ & $5 \cdot 7$ & $10 \cdot 7$ \\
\hline \multirow[t]{2}{*}{16.6} & 0.08 & $14 \cdot 4$ & 0.55 & $2 \cdot 1$ & $4 \cdot 2$ & $1 \cdot 1$ & $1 \cdot 5$ & $2 \cdot 7$ \\
\hline & 0.30 & $13 \cdot 7$ & 0.50 & $8 \cdot 2$ & 16.4 & 8.0 & $4 \cdot 0$ & $12 \cdot 4$ \\
\hline \multirow[t]{2}{*}{$55 \cdot 5$} & 0.08 & $30 \cdot 5$ & 0.96 & $2 \cdot 5$ & $5 \cdot 0$ & $1 \cdot 1$ & $1 \cdot 8$ & $3 \cdot 2$ \\
\hline & $0 \cdot 30$ & $14 \cdot 4$ & 0.39 & $11 \cdot 1$ & $22 \cdot 2$ & 6.8 & $5 \cdot 2$ & $17 \cdot 8$ \\
\hline
\end{tabular}

Table 3. Effect of $D$ on enzymic activities from cell-free extracts of glycerol-limited steady-state cultures of $C$. butyricum DSM 5431

Data in parentheses are SD values from four determinations. NP, not possible.

\begin{tabular}{|c|c|c|c|c|c|c|c|}
\hline \multirow[t]{3}{*}{ Enzyme } & \multicolumn{7}{|c|}{ Specific activity $\left(\mu \mathrm{mol} \mathrm{min} \mathrm{mg}^{-1} \mathrm{mg}^{-1}\right)$} \\
\hline & \multicolumn{5}{|c|}{ Glycerol (108.5 mM) } & \multicolumn{2}{|c|}{ Glucose (5.55 mM) } \\
\hline & 0.04 & 0.08 & $0 \cdot 15$ & $0 \cdot 26$ & $0 \cdot 30$ & 0.08 & $0 \cdot 30$ \\
\hline $\begin{array}{l}\text { Glycerol } \\
\text { dehydrogenase }\end{array}$ & $1.43(0.32)$ & $1 \cdot 61(0 \cdot 35)$ & $1.72(0 \cdot 34)$ & $1.75(0 \cdot 40)$ & $2 \cdot 41(0 \cdot 43)$ & $\mathrm{NP}$ & NP \\
\hline $\begin{array}{l}\text { 1,3-PD } \\
\text { dehydrogenase }\end{array}$ & $0.58(0.11)$ & $0.74(0 \cdot 18)$ & $0 \cdot 87(0 \cdot 26)$ & $1.07(0.32)$ & $1 \cdot 22(0 \cdot 19)$ & NP & NP \\
\hline Diol dehydratase & $0.24(0.06)$ & $0 \cdot 27(0 \cdot 07)$ & $0 \cdot 32(0 \cdot 08)$ & $0.35(0.08)$ & $0.39(0.09)$ & $\mathrm{NP}$ & $\mathrm{NP}$ \\
\hline Thiolase & $0 \cdot 185(0 \cdot 027)$ & $0.178(0.025)$ & $0 \cdot 177(0 \cdot 026)$ & $0 \cdot 181(0 \cdot 032)$ & $0.153(0.022)$ & $0.169(0 \cdot 025)$ & $0 \cdot 160(0 \cdot 022)$ \\
\hline Acetate kinase & $0.57(0.17)$ & $0.89(0 \cdot 21)$ & $0.72(0 \cdot 22)$ & $1 \cdot 01(0 \cdot 17)$ & $9 \cdot 04(0 \cdot 85)$ & $4 \cdot 78(0 \cdot 76)$ & $5.92(0 \cdot 83)$ \\
\hline Butyrate kinase & $0.54(0 \cdot 11)$ & $0.79(0 \cdot 17)$ & $0.89(0 \cdot 21)$ & $1 \cdot 23(0 \cdot 23)$ & $1 \cdot 20(0 \cdot 31)$ & $2 \cdot 71(0.41)$ & $3.57(0 \cdot 46)$ \\
\hline Hydrogenase & $0.11(0.03)$ & $0.03(0.01)$ & $0.025(0.012)$ & $0.027(0.014)$ & $0.037(0.014)$ & $0.080(0.023)$ & $0 \cdot 164(0 \cdot 04)$ \\
\hline Phosphoroclastic & $0.028(0.011)$ & $0.036(0.013)$ & $0.04(0.018)$ & $0.033(0.011)$ & $0.048(0.021)$ & $0.091(0.027)$ & $0 \cdot 107(0.034)$ \\
\hline $\begin{array}{l}\text { fd-NAD } \\
\text { reductase }\end{array}$ & $0 \cdot 0091$ & $0 \cdot 011$ & 0.0095 & $0 \cdot 0128$ & $0 \cdot 009$ & 0.007 & $0 \cdot 007$ \\
\hline $\begin{array}{l}\text { NADH-fd } \\
\text { reductase }\end{array}$ & $0 \cdot 011$ & 0.0096 & $0 \cdot 0083$ & 0.0093 & $0 \cdot 008$ & 0.009 & $0 \cdot 013$ \\
\hline
\end{tabular}

\section{Levels of key metabolic enzyme activities from cell extracts of continuous glycerol-limited steady-state cultures of C. butyricum}

As seen in Table 3 , in the steady-state cultures, in vitro glycerol dehydrogenase, 1,3-PD dehydrogenase and diol dehydratase activities were higher under conditions giving higher in vivo specific consumption or production rates. This correlation between in vitro activities and in vivo consumption and formation rates can also be observed in Fig. 4 where these parameters have been plotted against each other for a number of different steady-state conditions. In contrast, whatever the value of $D$, the specific activities of thiolase were relatively constant. Concomitant with the increase in $D$, there was an increase of acetate kinase activity which was significantly higher at $0.30 \mathrm{~h}^{-1}$, corresponding to the switch in acetate and butyrate formation (Fig. 3). From the lowest $(D=$ $\left.0.04 \mathrm{~h}^{-1}\right)$ to the highest $\left(D=0.30 \mathrm{~h}^{-1}\right) D$ values, acetate kinase increased $15 \cdot 7$-fold and butyrate kinase $2 \cdot 2$-fold. All the oxidoreductases exhibited maximum activity with $\mathrm{NAD}^{+}$: $\mathrm{fd}-\mathrm{NAD}^{+}$reductase, NADH-fd reductase, glycerol-NAD ${ }^{+}$oxidoreductase and $\mathrm{PD}-\mathrm{NAD}^{+}$oxidoreductase activities were $6 \cdot 1$-, 8.8-, 7.6- and 6.2-fold higher, respectively, than with $\mathrm{NADP}^{+}$. The values of the phosphoroclastic reaction were fairly constant whereas hydrogenase activity was significantly higher at the low $D$ of $0.04 \mathrm{~h}^{-1}$, and decreased about 3.5 -fold at $0.30 \mathrm{~h}^{-1}$. The electrons which are ultimately transferred to $\mathrm{NAD}^{+}$by the $\mathrm{fd}-\mathrm{NAD}^{+}$reductase are obtained from the oxidation of pyruvate via the endogenous pyruvate dehydrogenase, hence the $\mathrm{fd}-\mathrm{NAD}^{+}$reductase activity was dependent on the phosphoroclastic reaction and is in the same range of activity, i.e. in the range of nmol. fd- $\mathrm{NAD}^{+}$and 

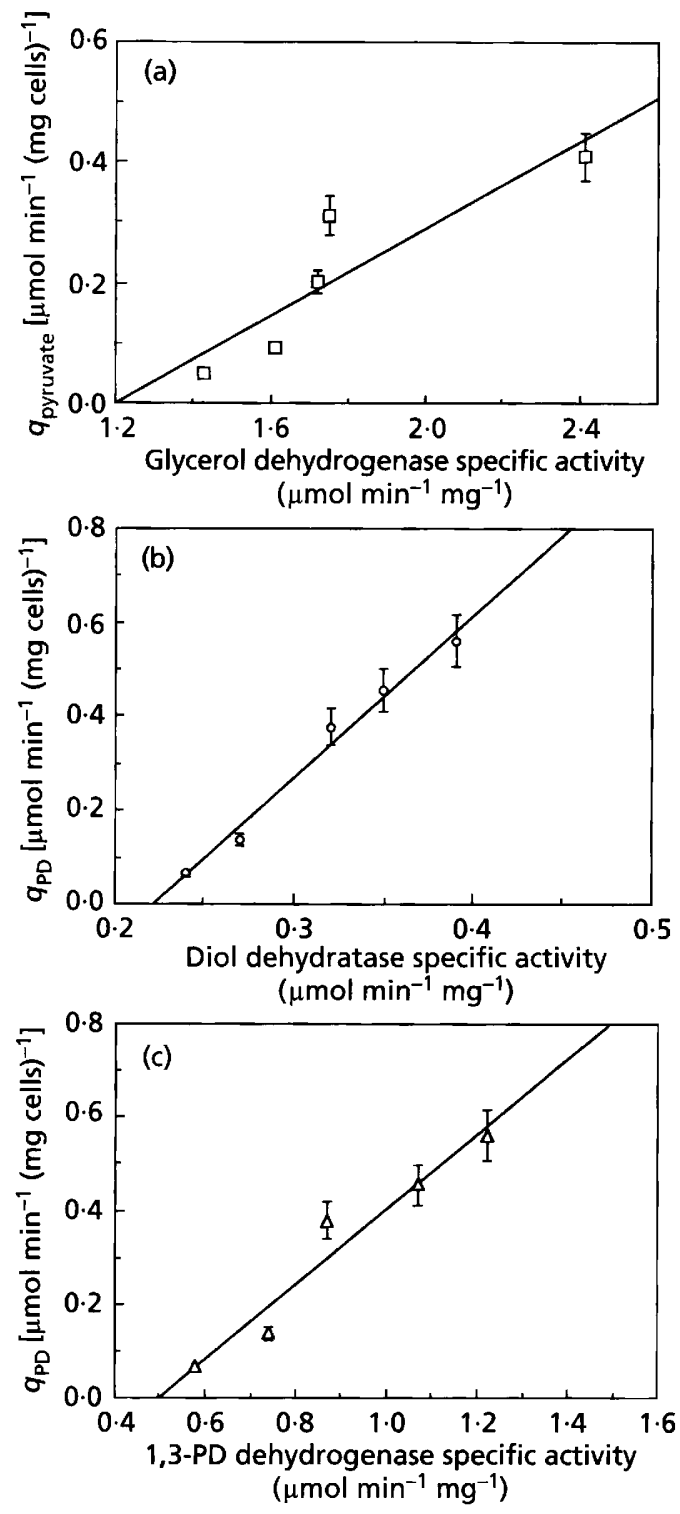

Fig. 4. In vivo specific carbon fluxes as a function of in vitro specific enzyme activities in a continuous culture of $C$. butyricum. The glycerol input concentration was $108 \mathrm{mM}$. (a) In vivo specific carbon fluxes through the glyceraldehyde-3-P path versus specific glycerol dehydrogenase activity. (b, c) In vivo specific carbon fluxes through the 1,3-PD pathway versus specific diol dehydratase activity (b) and versus 1,3-PD dehydrogenase activity (c).

$\mathrm{NADH}-\mathrm{fd}$ reductase activities were detected with almost the same ratio at all $D$ values.

\section{Levels of key metabolic enzyme activities from cell extracts of continuous glucose-limited steady-state cultures of $\mathrm{C}$. butyricum}

No activity of glycerol dehydrogenase, 1,3-PD dehydrogenase and diol dehydratase was detected in cell-free extracts of glucose-grown cells. Thiolase activity was similar to that found in extracts of cells grown on glycerol.
The level of this enzyme is low; for comparison, in $C$. pasteurianum ATCC 6013, thiolase activity determined in the same physiological direction was around $1 \mu \mathrm{mol} \mathrm{min}{ }^{-1} \mathrm{mg}^{-1}$, i.e. sixfold higher. High levels of acetate kinase were found in cell-free extracts of glucosegrown cells. Butyrate kinase, hydrogenase and phosphoroclastic activities were increased in glucose-grown cells compared to glycerol-grown cells. Nevertheless, the hydrogenase activity of $C$. butyricum DSM 5431 is weak, for example we found a specific activity around $7 \cdot 4 \mu \mathrm{mol} \mathrm{min}{ }^{-1} \mathrm{mg}^{-1}$, i.e. $11 \cdot 5$-fold higher, in cell-free extracts of $C$. pasteurianum ATCC 6013. The specific activities of $\mathrm{fd}-\mathrm{NAD}{ }^{+}$reductase and $\mathrm{NADH}-\mathrm{fd}$ reductase were in the same range for cells grown either on glucose or on glycerol.

\section{Intracellular acetyl-CoA, $\mathrm{NAD}^{+}$and $\mathrm{NADH}$ pools of continuous steady-state cultures of $C$. butyricum}

The levels of $\mathrm{NAD}^{+}, \mathrm{NADH}$ and acetyl-CoA for the steady-states on glycerol and on glucose are shown in Table 4. In glycerol-grown cells the concentrations of acetyl-CoA, NADH and total $\mathrm{NAD}^{+}+\mathrm{NADH}$ increased sharply with the increase in $D$ and a switch in the $\mathrm{NAD}^{+} / \mathrm{NADH}$ ratios was observed above a $D$ of $0.15 \mathrm{~h}^{-1}$. In glucose-grown cells, the levels of NADH were always higher than the $\mathrm{NAD}^{+}$levels and the concentrations of the three compounds were at or well above the levels found in glycerol-grown cultures. Fluorometric and colorimetric methods for $\mathrm{NAD}^{+}$and $\mathrm{NADH}$ assay gave similar results.

\section{DISCUSSION}

Our results show clearly that growing $C$. butyricum in continuous culture at different growth rates and under glycerol limitation did not affect the conversion of glycerol into 1,3-PD. This differs dramatically from $C$. acetobutylicum, another producer of reduced compounds, where low $D$ values were associated with a rise in solvent formation and high $D$ values with the accumulation of acetic and butyric acids (Bahl \& Gottschalk, 1985; Fick et al., 1985). The relatively constant value of the $q_{\mathrm{PD}} / q_{\text {glyceraldehyde }}$ ratio in the fermentation of glycerol suggests the presence of regulatory mechanisms that precisely partition the flow between the competing pathways. The enzymes glycerol dehydrogenase, diol dehydratase and 1,3-PD dehydrogenase constitute a branch point and we found increasing levels of these enzyme activities with increasing $D$, thus contributing to a constant ratio of carbon flux through that branch point (Fig. 2). This allows us to explain the minor changes found for glycerol conversion into 1,3-PD, whatever the value of the $D$. The main observation for high $D$ values was the decrease in butyrate production and a concomitant increase in acetate formed (Table 1). These changes in the acetate/butyrate ratio were also observed in C. butyricum growing on glycerol (Günzel, 1991) and in C. tyrobutyricum (Michel-Savin et al., 1990) and C. butyricum growing on glucose (Crabbendam et al., 1985). The production of 
Table 4. Nucleotide levels of continuous steady-state C. butyricum DSM 5431 with glucose or glycerol as substrate

Data in parentheses are SD values from six determinations from three separated cultures measured either by colorimetric or fluorometric methods.

\begin{tabular}{|c|c|c|c|c|c|c|}
\hline \multirow[t]{2}{*}{ Substrate } & \multirow[t]{2}{*}{$D\left(\mathbf{h}^{-1}\right)$} & \multicolumn{5}{|c|}{ Nucleotide conch $\left[\mu \mathrm{mol}(\mathrm{g} \text { dry cell wt })^{-1}\right]$} \\
\hline & & $\mathbf{N A D}^{+}$ & NADH & $\mathbf{N A D}^{+}+\mathbf{N A D H}$ & NADH/NAD ${ }^{+}$ & Acetyl-CoA \\
\hline \multirow{5}{*}{$\begin{array}{l}\text { Glycerol } \\
(108.5 \mathrm{mM})\end{array}$} & $0 \cdot 04$ & $7 \cdot 5(0 \cdot 3)$ & $3.90(0.2)$ & $11 \cdot 4$ & 0.52 & $12 \cdot 1(0 \cdot 8)$ \\
\hline & $0 \cdot 08$ & $12 \cdot 1(0 \cdot 7)$ & $7.5(0.5)$ & $19 \cdot 6$ & $0 \cdot 62$ & $11 \cdot 0(0 \cdot 7)$ \\
\hline & $0 \cdot 15$ & $14.5(1.0)$ & $8 \cdot 2(0 \cdot 6)$ & $22 \cdot 7$ & 0.56 & $15 \cdot 3(0 \cdot 9)$ \\
\hline & $0 \cdot 26$ & $8.6(0.6)$ & $15.9(0 \cdot 9)$ & $24 \cdot 5$ & $1 \cdot 84$ & $17 \cdot 2(1 \cdot 2)$ \\
\hline & $0 \cdot 30$ & $15 \cdot 3(0 \cdot 9)$ & $24 \cdot 5(2 \cdot 2)$ & $39 \cdot 8$ & $1 \cdot 60$ & $24 \cdot 1(1.9)$ \\
\hline \multirow{2}{*}{$\begin{array}{l}\text { Glucose } \\
(5.55 \mathrm{mM})\end{array}$} & $0 \cdot 08$ & $12 \cdot 2(0 \cdot 8)$ & $20 \cdot 8(1 \cdot 2)$ & $33 \cdot 0$ & $1 \cdot 70$ & $24 \cdot 1(1 \cdot 2)$ \\
\hline & $0 \cdot 30$ & $12 \cdot 2(0 \cdot 7)$ & $25 \cdot 3(1 \cdot 3)$ & $37 \cdot 5$ & $2 \cdot 06$ & $38 \cdot 8(2 \cdot 3)$ \\
\hline \multirow{2}{*}{$\begin{array}{l}\text { Glucose } \\
(16.5 \mathrm{mM})\end{array}$} & $0 \cdot 08$ & $12 \cdot 4(0 \cdot 8)$ & $25 \cdot 2(1 \cdot 2)$ & $37 \cdot 6$ & $2 \cdot 00$ & $15 \cdot 2(0 \cdot 9)$ \\
\hline & $0 \cdot 30$ & $12 \cdot 8(0 \cdot 7)$ & $28.4(1 \cdot 4)$ & $41 \cdot 2$ & $2 \cdot 20$ & $33.4(2.0)$ \\
\hline \multirow{2}{*}{$\begin{array}{l}\text { Glucose } \\
(55.5 \mathrm{mM})\end{array}$} & $0 \cdot 08$ & $17 \cdot 1(1 \cdot 0)$ & $20 \cdot 3(1 \cdot 2)$ & $37 \cdot 4$ & $1 \cdot 18$ & $23 \cdot 1(1 \cdot 1)$ \\
\hline & $0 \cdot 30$ & $11 \cdot 1(0 \cdot 6)$ & $27 \cdot 4(1 \cdot 6)$ & $38 \cdot 5$ & $2 \cdot 45$ & $32.3(1.9)$ \\
\hline
\end{tabular}

acetate or butyrate constitutes another important branch point and when the carbon flux switches from butyric acid to acetic acid formation we observed a corresponding shift in the relative activities of acetate and butyrate kinase, whereas the specific activities of thiolase were not affected by changes in $D$. Glucose- or glycerol-grown cells have in common the pathway from glyceraldehyde-3-P to pyruvate and whatever the carbon source, $q_{\text {pyruvate }}$ increased as $D$ increased producing large amounts of acetyl-CoA. The intracellular concentration of acetylCoA increased from $12.1 \mu \mathrm{mol} \mathrm{g}^{-1}$ at $D=0.04 \mathrm{~h}^{-1}$ to $24.1 \mu \mathrm{mol} \mathrm{g}^{-1}$ at $D=0.30 \mathrm{~h}^{-1}$ when glycerol was the carbon source. The shift in carbon flux took place at a $D$ of roughly $0.26 \mathrm{~h}^{-1}$, when $17 \cdot 2 \mu \mathrm{mol} \mathrm{g}^{-1}$ of acetyl-CoA was produced.

The thiolase that converts acetyl-CoA to acetoacetyl-CoA may be the bottleneck for carbon flux to butyrate biosynthesis since our results show that its level did not change significantly with $D$. This suggests that the acetate pathway is an important pathway of overflow metabolism when the specific rate of acetyl-CoA formation increases above a critical threshold. For a $q_{\text {pyruvate }}$ which increased 6.6-fold from $D=0.04 \mathrm{~h}^{-1}$ to $D=0.26 \mathrm{~h}^{-1}$, the intracellular NADH increased fourfold, whereas between $D$ $=0.26$ and $0.30 \mathrm{~h}^{-1}$ the intracellular concentration increased less than twofold. This can be explained by the fact that between $D=0.04$ and $0.26 \mathrm{~h}^{-1}$, the formation of both $\mathrm{PD}$ and butyrate regenerates $\mathrm{NAD}^{+}$, whereas above $D=0 \cdot 26 \mathrm{~h}^{-1}, \mathrm{NADH}$ was used principally (high level of intracellular $\mathrm{NADH}$ ) for $\mathrm{PD}$ formation. Considering that oxidation of NADH by 1,3-PD dehydrogenase was linked to the production of 3-HPA by diol dehydratase, the fact that the intracellular concentrations of $\mathrm{NADH}$ were extremely high demonstrates that diol dehydratase activity was the rate-limiting step in 1,3-PD formation; in that way 3-HPA does not accumulate. This limitation was maintained whatever the rate of carbon flux since the activities of all three enzymes (glycerol dehydrogenase, 1,3-PD dehydrogenase and glycerol dehydratase) were regulated in similar ways (Fig. 4). We suggest that the high concentration of NADH in the cell prevents the accumulation of 3-HPA which is a very reactive and toxic compound that has been shown to be excreted by Lactobacillus reuteri and termed reuterin (Axelsson $e t$ al., 1989; Chung et al., 1989). It is a bioactive substance which at low concentrations inhibits the growth of Grampositive and -negative bacteria and lower eukaryotic organisms.

A number of investigators have noted the more reduced state of glycerol in comparison to glucose and suggested that glycerol could stimulate hydrogen production (Heyndrickx et al., 1991a, Dabrock et al., 1992). In fact, growth of $C$. butyricum on glycerol induced the four enzymes of the dha regulon (Heyndrickx et al., 1991b, Tong et al., 1991) and regenerated the excess reducing equivalents via the butyrate pathway and principally via the highly active 1,3-PD dehydrogenase. In glycerol catabolism, our data indicate that the NADH produced by glycerol dehydrogenase and glyceraldehyde-3-P dehydrogenase is not sufficient for 1,3-PD formation and that part of the reduced fd produced by the pyruvate-fd oxidoreductase is reoxidized by $\mathrm{fd}-\mathrm{NAD}^{+}$reductase activity to produce NADH.

The reduction of $\mathrm{NAD}^{+}$by reduced fd and the reductase occurred via the endogenous pyruvate dehydrogenase and hence the fd-NAD ${ }^{+}$reductase activities were dependent on the phosphoroclastic reaction. In cell-free extracts of glycerol-limited cultures, these two reactions showed similar specific activities; between 0.04 and 
$0 \cdot 26 \mathrm{~h}^{-1}$ the phosphoroclastic activity was $2 \cdot 6$ - to $4 \cdot 2$-fold higher than the fd-NAD ${ }^{+}$reductase activity. When cells were grown on glycerol, an $80 \%$ decrease of hydrogenase activity was noted compared to growth on glucose at all $D$ values. The low level of hydrogenase associated with the fd- $\mathrm{NAD}^{+}$reductase activity contributed to production of NADH. This kind of regulation, a high level of intracellular $\mathrm{NADH}$ and a decrease of hydrogenase activity, has been reported elsewhere (Girbal et al., 1995).

In contrast, growth on glucose generates reducing equivalents which are released in excess in the glycolytic pathway and are reoxidized by $\mathrm{NADH}-\mathrm{fd}$ reductase and higher levels of hydrogenase (Table 3 ). In glucose-grown cells, the low level of thiolase (Table 3 ) and the high intracellular concentration of acetyl-CoA and of NADH (Table 4) suggest that the butyric pathway is a bottleneck for the carbon flux and hence is insufficient to regenerate the NADH produced by glycolysis or the acetyl-CoA produced by the phosphoroclastic reaction, and in turn a high level of NADH and acetyl-CoA explain the low amount of glucose used. On the basis of the results presented it is apparent that C. butyricum DSM 5431 is not adapted to grow at high glucose concentrations since the low specific formation rate of butyric acid leads to increased levels of acetyl-CoA and NADH. This high level of NADH was reported to inhibit glyceraldehyde-3$P$ dehydrogenase in C. acetobutylicum (Girbal \& Soucaille, 1994) but surprisingly, the specific rates of pyruvate formation were almost the same either on glucose or glycerol whatever the $\mathrm{NADH} / \mathrm{NAD}^{+}$ratio. We can explain a higher carbon flow on glycerol by the fact that $\mathrm{NADH}$ is reoxidized by both butyric and PD pathways. Nevertheless, a high flux of glycerol also led to a high level of NADH due to the limited production of 3-HPA by diol dehydratase. The variation of $\mathrm{NAD}^{+}$and $\mathrm{NADH}$ content with $D$ values has already been reported in a Pseudomonas sp. (Matin \& Gottschall, 1976). Because the reoxidation of NADH by 1,3-PD and butyrate biosynthesis are limiting steps, catabolism of the carbon substrate may be facilitated by a concomitant increase in NAD $^{+}$ biosynthesis which would tend to maintain the $\mathrm{NADH} / \mathrm{NAD}^{+}$ratios. Usually intracellular $\mathrm{NAD}^{+}$plus NADH concentrations in clostridia are around 7-14 $\mu \mathrm{mol}$ (g dry cell wt) ${ }^{-1}$ (Meyer \& Papoutsakis, 1989; Girbal \& Soucaille, 1994); nevertheless values as high as $39 \cdot 8 \mu \mathrm{mol}$ ( $\mathrm{g}$ dry cell wt) ${ }^{-1}$ were reported in C. kluyveri (Decker \& Pfitzer, 1972). Glycerol dehydratase is rather difficult to measure and no detailed investigations of this enzyme have been reported in clostridia. From our results it is apparent that the glycerol dehydratase plays a key function in glycerol catabolism and remains to be more fully studied.

\section{ACKNOWLEDGEMENTS}

The authors wish to thank Dr H. Biebl and Ms A. Reimann for helpful discussions and are grateful to E. Guedon and E. Spiesser for skilful co-operation in part of the experiments. This work was supported by the commission of the European communities AAIR programme: Contract no. AIR 2-C'T93-0825 (DG 12 SSMA).

\section{REFERENCES}

Axelsson, L., Chung, T. C., Dobrogosz, W. J. \& Lindgren, S. E. (1989). Production of a broad spectrum antimicrobial substance by Lactobacillus reuteri. Microb Ecol Health Dis 2, 131-136.

Bahl, H. \& Gottschalk, G. (1985). Parameters affecting solvent production by Clostridium acetobutylicum in continuous culture. Biotechnol Bioeng 514, 217-223.

Berndt, H. \& Schlegel, H. G. (1975). Kinetics and properties of $\beta$ ketothiolase from Clostridium pasteurianum. Arch Microbiol 103, 21-30.

Biebl, H. (1991). Glycerol fermentation of 1,3-propanediol by Clostridium butyricum. Measurement of product inhibition by use of a pH-auxostat. Appl Microbiol Biotechnol 35, 701-705.

Biebl, H. \& Pfenning, N. (1982). Isolation of members of the family Rhodospirillaceae. In The Prokaryotes, pp. 267-273. Edited by M. P. Starr, H. Stolp, H. G. Trüper, A. Balows \& H. G. Schlegel. Berlin: Springer-Verlag.

Biebl, H., Marten, S., Hippe, H. \& Deckwer, W. D. (1992). Glycerol conversion to 1,3-propanediol by newly isolated clostridia. Appl Microbiol Biotecbnol 36, 592-597.

Blusson, H., Petitdemange, H. \& Gay, R. (1981). A new, fast and sensitive assay for NADH-ferredoxin oxidoreductase detection in clostridia. Anal Biochem 110, 176-181.

Bradford, M. (1976). A rapid and sensitive method for the quantitation of microgram quantities of protein utilizing the principle of protein-dye binding. Anal Biochem 72, 248-254.

Chung, T. C., Axelsson, L., Lindgren, S. E. \& Dobrogosz, W. J. (1989). In vitro studies on reuterin synthesis by Lactobacillus reuteri. Microb Ecol Health Dis 2, 137-144.

Crabbendam, P. M., Neijssel, O. M. \& Tempest, D. W. (1985). Metabolic and energetic aspects of the growth of Clostridium butyricum on glucose in chemostat culture. Arch Microbiol 142, 375-382.

Dabrock, B., Bahl, H. \& Gottschalk, G. (1992). Parameters affecting solvent production by Clostridium pasteurianum. Appl Microbiol Biotechnol 58, 1233-1239.

Decker, K. (1965). Acetyl-CoA. In Methods of Enzymatic Analysis, 2nd edn, pp. 419-424. Edited by H. U. Bergmeyer. New York: Academic Press.

Decker, K. \& Pfitzer, S. (1972). Determination of steady-state concentrations of adenine nucleotides in growing Clostridium kluyveri cells by biosynthetic labelling. Anal Biochem 50, 529-539.

Fick, M., Pierrot, P. \& Engasser, J. M. (1985). Optimal conditions for long-term stability of acetone-butanol production by continuous cultures of Clostridium acetobutylicum. Biotechnol Lett 7 , 503-508.

Girbal, L. \& Soucaille, P. (1994). Regulation of Clostridium acetobutylicum metabolism as revealed by mixed-substrate steadystate continuous cultures: role of NADH/NAD ratio and ATP pool. J Bacteriol 176, 6433-6438.

Girbal, L., Vasconcelos, I., Saint-Amans, S. \& Soucaille, P. (1995). How neutral red modified carbon and electron flow in Clostridium acetobutylicum grown in chemostat culture at neutral $\mathrm{pH}$. FEMS Microbial Rev 16, 151-162.

Günzel, B. (1991). Mikerobielle berstellung von 1,3-Propanediol durch Clostridium butyricum und adsorptive aufarbritung von diolen. $\mathrm{PhD}$ thesis, University of Braunschweig.

Gunzel, B., Yonsel, S. \& Deckwer, W. D. (1991). Fermentative production of 1,3-propanediol from glycerol by Clostridium butyricum up to a scale of $2 \mathrm{~m}^{3}$. Appl Microbiol Biotechnol 36, 289-294.

Heyndrickx, M., De Vos, P. \& Deley, J. (1991a). Fermentation 
characteristics of Clostridium pasteurianum LMG 3285 grown on glucose and mannitol. J Appl Bacteriol 70, 52-58.

Heyndrickx, M., De Vos, P., Vancanneyt, M. \& Deley, J. (1991b). The fermentation of glycerol by Clostridium butyricum LMG $1212 \mathrm{t} 2$ and 1213 t 1 and Clostridium pasteurianum LMG 3285. Appl Microbiol Biotechnol 34, 637-642.

Junelles, A. M., Janati-Idrissi, R., Petitdemange, H. \& Gay, R. (1988). Iron effect on acetone-butanol fermentation. Curr Microbiol 17, 299-303.

Jungermann, K., Thauer, R. K., Leimenstoll, G. \& Decker, K. (1973). Function of reduced pyridine nucleotide-ferredoxin oxidoreductases in saccharolytic clostridia. Biochim Biophys Acta 305, $268-280$.

Klingenberg, M. (1965). Nicotinamide-adenine dinucleotides (NAD, NADP, NADH, NADPH). Spectrophotometric and fluorometric methods. In Methods of Enzymatic Analysis Vol. 4, 2nd edn, pp. 2045-2059. Edited by H. U. Bergmeyer. New York: Academic Press.

Lipmann, F. \& Tuttle, L. C. (1945). A specific micromethod for determination of acyl-phosphates. J Biol Chem 159, 21-28.

Lynen, F., Wesseley, L., Wieland, O. \& Rueff, L. (1952). Zur $\beta$ oxidation von Fettsäuren. Angrew Chem 64, 687.

Matin, A. \& Gottschall, J. C. (1976). Influence of dilution rate on $\mathrm{NAD}(\mathrm{P})$ and NAD $(\mathrm{P}) \mathrm{H}$ concentrations and ratios in a Pseudomonas sp. grown in continuous culture. J Gen Microbiol 94, 333-341.

Meyer, C. L. \& Papoutsakis, E. T. (1989). Increased levels of ATP and NADH are associated with increased solvent production in continuous cultures of Clostridium acetobutylicum. Appl Microbiol Biotechnol 30, 450-459.

Michel-Savin, D., Marchal, R. \& Vandecasteele, J. P. (1990). Butyrate production in continuous culture of Clostridium tyrobutyricum : effect of end-product inhibition. Appl Microbiol Biotechnol $33,127-131$.
Mortenson, L. E., Valentine, R. C. \& Carnahan J. E. (1963). Ferredoxin in the phosphoroclastic reaction of pyruvic acid and its relation to nitrogen fixation in Clostridium pasteurianum. J Biol Chem 238, 794-800.

Petitdemange, H., Cherrier, C., Raval, G. \& Gay R. (1976). Regulation of the NADH-ferredoxin oxidoreductases in clostridia of butyric group. Biochim Biophys Acta 421, 334-347.

Ruch, F. E., Lengeler, J. \& Lin, E. C. (1974). Regulation of glycerol catabolism in Klebsiella aerogenes. J Bacteriol 119, 50-56.

Tubbs, P. K. \& Garland, P. B. (1969). Assays of coenzyme A and some acyl derivatives. Methods Enzymol 8, 535-551.

Tong, I. T., Liao, H. H. \& Cameron, D. C. (1991). 1,3-Propanediol production by Escherichia coli expressing genes from the Klebsiella pneumoniae dha regulon. Appl Environ Microbiol 57, 3541-3546.

Toraya, T., Ushio, K., Fukui, S. \& Hogenkamp, H. P. C. (1977). Studies on the mecanism of the adenosylcobalamin-dependent diol dehydratase reaction by the use of analogs of the coenzyme. $J$ Biol Chem 252, 963-970.

Vasconcelos, I., Girbal, L. \& Soucaille, P. (1994). Regulation of carbon and electron flow in Clostridium acetobutylicum grown in chemostat culture at neutral $\mathrm{pH}$ on mixture of glucose and glycerol. J Bacteriol 176, 1443-1450.

Wimpenny, J. W. T. \& Firth, A. (1972). Levels of nicotinamide adenine dinucleotide and reduced nicotinamide adenine dinucleotide in facultative bacteria and the effect of oxygen. $J$ Bacteriol 111, 24-32.

Woods, D. R. (1993). The Clostridia and Biotechnology. Edited by D. R. Woods. Stoneham, MA: Butterworth-Heinemann.

Received 28 July 1995; revised 20 December 1995; accepted 10 January 1996. 